\title{
Synthesis of Diamond-like Carbon by PECVD on Different Substrates for Fuel Cell Applications
}

\author{
Ibrahim Alaefour \\ Department of Mechanical and Mechatronics Engineering \\ University of Waterloo, Waterloo, Ontario N2L 3G1 \\ Ibrahim.Alaefour@uwaterloo.ca
}

\author{
Jian Zhao \\ Department of Mechanical and Mechatronics Engineering \\ University of Waterloo, Waterloo, Ontario N2L 3G1 \\ jian.zhao@uwaterloo.ca
}

\author{
Samaneh Shahgaldi \\ Department of Mechanical and Mechatronics Engineering \\ University of Waterloo, Waterloo, Ontario N2L 3G1 \\ samaneh.shahgaldi@uwaterloo.ca \\ Xianguo Li \\ Department of Mechanical and Mechatronics Engineering \\ University of Waterloo, Waterloo, Ontario N2L 3G1 \\ xianguo.li@uwaterloo.ca
}

\begin{abstract}
Lower cost, lighter weight, and higher electrical conductivity are among many advantages of using metallic bipolar plates (BPs) over the conventional graphitic materials in PEM fuel cell applications. In this study, diamond-like carbon (DLC) coatings are deposited on top surfaces of stainless steel (SS316) and Aluminum (A15052) substrates via Plasma Enhanced Carbon Vapor Deposition (PECVD) in order to increase the durability. Further, the effect of different plasma power intensities and type of precursor gases, including methane $\left(\mathrm{CH}_{4}\right)$ and acetylene $\left(\mathrm{C}_{2} \mathrm{H}_{2}\right)$, on the growth of DLC films is studied. Various ex-situ characterization techniques have been used to examine the strength of adhesion, morphologies, structures/compositions, and wettability of the DLC coatings. It is found that coatings produced from $\mathrm{CH}_{4}$ gas show superior adhesion in comparison to those obtained from the $\mathrm{C}_{2} \mathrm{H}_{2}$ gas. Results indicate that higher deposition power intensity can produce more $\mathrm{sp}^{3}$ bonds than $\mathrm{sp}^{2}$ bonds. It is also determined that the type of the metallic substrates has predominant roles on the morphology of the DLC coatings. In addition, a moderate power intensity of $250 \mathrm{~W}$ results in desirable properties in DLC, including adhesion and wettability, compared to higher and lower plasma power intensities.
\end{abstract}

Keywords- Proton exchange membrane fuel cell; Bipolar plates; Diamond-like carbon.

\section{INTRODUCTION}

Bipolar plates (BPs) are one of the crucial components in polymer electrolyte membrane (PEM) fuel cells. They conduct electrons between adjoining cells, distribute reactants, facilitate water and heat management, and provide mechanical support. To accomplish these functions, bipolar plates must exhibit a number of desirable mechanical and surface properties. However, most commercial bipolar plates are made of heavy- graphite and are considered to be the bulkiest and the second most-expensive component in the manufacture of PEM fuel cell stacks [1]. Due to the technical and cost requirements of BPs [1-3], metallic bipolar plates have received considerable attention to replace conventional graphite materials, but their durability inside the acidic PEM fuel cell environment is a challenging issue. Various surface modifications and protective coatings have been investigated, including [4]: noble metals such as gold [5], metal nitrides, and metal carbides. In the last decade, diamond-like carbon (DLC) has been considered an innovative candidate as a coating material for metallic BPs in PEM Fuel Cells [6]. In general, DLC can be formed as a thin film at relatively low deposition temperatures on metallic substrates. One of the most suitable DLC deposition techniques is Plasma Enhanced Chemical Vapor Deposition (PECVD) [79]. Carbon-based layer is deposited on stainless steel (SS304) via PECVD, and the coating sample presents the lower interfacial contact resistance in comparison to the SS304 without coating [10]. In other work, a $1 \mu \mathrm{m}$-thin layer of nickel is applied between the SS304 and carbon-base coating to improve adhesion [11]. The electrical conductivity of DLC film under different voltages is also reported [12]. Due to the potential advantages of using aluminum, different carboncomposite coatings for aluminum-base bipolar plates have also been investigated [13] [14]. However, information about DLC coating on the aluminum surfaces is limited. Therefore, the objective of this work is to investigate the effect of deposition parameters on the DLC properties for metallic-base substrates (stainless steel SS316 and aluminum A15052).

\section{EXPERIMENTAL AND CHARACTERIZATIONS}

The DLC coating is deposited on Al5052 and SS316 substrates by using the fully automated INTLVAC's AUTOSYS control system. $\mathrm{CH}_{4}$ and $\mathrm{C}_{2} \mathrm{H}_{2}$ are separately used as a precursor gas, and the carrier gas is argon. Different plasma power intensities of 70, 250, and $1000 \mathrm{~W}$ are applied in 
order to investigate its impact of plasma power on the various characteristics of DLC coatings, whereas the argon gas percentage is fixed at $30 \%$ and the deposition time is a constant of $74 \mathrm{~min}$. Various ex-situ characterization methods are employed to investigate the properties of the deposited films. Scanning electron microscopy is used to study the morphology of the prepared samples. Since the adhesion of the coating DLC films is one of the most challenging tasks of surface engineering, tape pull-off tests are used to check the coatings' adhesion to the metallic substrates. The morphology of the coated film is investigated by field emission-scanning electron microscopy (FE-SEM). Further, X-ray photoelectron (XPS) spectroscopy is commonly used for quantitative comparison between the molecule compositions existing on the coated surface. The DLC surface wettability indicates the hydrophobicity behavior of the BP coatings in order to determine whether they are suitable for PEM Fuel cell applications. The surface wettabilities of the DLC coatings on different A15052 and SS316 samples are evaluated by measuring the static contact angle $(\theta)$, a characterization technique that uses a Ramé-Hart contact angle apparatus.

\section{RESULTS}

\section{A. Adhesion}

Table 1 summarizes the results of the adhesion tests between the DLC coatings on SS316 and Al5052 substrates, under the classifications as passed, failed, and partially failed. It shows the impact of varying the precursor gas between acetylene $\left(\mathrm{C}_{2} \mathrm{H}_{2}\right)$ and methane $\left(\mathrm{CH}_{4}\right)$, and the power intensities between $70 \mathrm{~W}$ and $250 \mathrm{~W}$, then $1000 \mathrm{~W}$ on the adhesion of the DLC coatings with the constant carrier gas (argon) percentage of $30 \%$ and deposition time of $74 \mathrm{~min}$.

TABLE 1. ADHESION TESTS OF DLC COATINGS ON SS316 AND AL5052 SUBSTRATES:

\begin{tabular}{|c|c|c|c|c|c|}
\hline \multicolumn{4}{|c|}{ Deposition Parameters } & $\begin{array}{l}\text { Substrate } \\
\text { Materials }\end{array}$ & $\begin{array}{c}\text { Substrate } \\
\text { Materials Al5052 }\end{array}$ \\
\hline $\begin{array}{c}\text { Power } \\
(W)\end{array}$ & $\begin{array}{l}\mathrm{H} / \mathrm{C} \\
\text { gas }\end{array}$ & $\begin{array}{l}A r \\
(\%)\end{array}$ & $\begin{array}{l}\text { Time } \\
(\mathrm{min})\end{array}$ & Pass/Failed & Pass/Failed \\
\hline 70 & $\mathrm{C}_{2} \mathrm{H}_{2}$ & 30 & 74 & Failed & Failed \\
\hline 250 & $\mathrm{CH}_{4}$ & 30 & 74 & Passed & Passed \\
\hline 1000 & $\mathrm{CH}_{4}$ & 30 & 74 & Failed & Passed \\
\hline
\end{tabular}

It is observed that employing $\mathrm{CH}_{4}$ gas can result in higher adhesion than $\mathrm{C}_{2} \mathrm{H}_{2}$ gas, especially with a moderate plasma power intensity of 250 for both A15052 and SS316 substrates. This adhesion enhancement can be attributed to the different growth mechanisms of carbon composites between $\mathrm{CH}_{4}$ gas and those produced from $\mathrm{C}_{2} \mathrm{H}_{2}$. This difference occurs because DLC generated by using $\mathrm{CH}_{4}$ produces more hydrogen in reaction, hence the etching reaction is developed during the deposition processes [15]. It is also noticed that increasing the plasma power intensity has a negative effect on the adhesion between the SS316 substrate and the coating. That is, a higher power intensity of $1000 \mathrm{~W}$ can result in poor DLC adhesion in comparison to $250 \mathrm{~W}$. The poor adhesion at higher plasma power intensity is associated with a fast deposition rate as well as the growth of thicker DLC films. Consequently, the residual stress is higher inside the films due to the noticeable increase in $\mathrm{sp}^{3}$ bonding fraction, as will be discussed by the XPS analysis. On the other hand, varying the plasma power intensity has a negligible impact on the adhesion of the DLC coating on Al 5052 substrates. These results signify the roles of the metallic substrate on the adhesion property.

\section{B. Morphology}

Figure 1 (a-d) shows the surface morphologies of two different DLC coatings deposited on SS316 and A15052 substrates at two different power intensities of $250 \mathrm{~W}$ and 1000 $\mathrm{W}$. These images are taken from the top surface without using any gold coating. Figure 1 ( $a$ and $b$ ) are obtained using SS316, while $30 \%$ of carrier gas is applied. These images show homogenous coverage, with the presence of big island-shaped regions (see the images with high magnification on top of the SEM images). Both surfaces are covered with dark and light particles, and this contrast can be attributed to the accumulation of particles with different electrical-conductivity properties. The DLC structure is basically amorphous carbon coordinated with $\mathrm{sp}^{2}$ and $\mathrm{sp}^{3}$ structures with different conductivity. It is expected that the $\mathrm{sp}^{3}$ bond is responsible for the mechanical properties, while $\mathrm{sp}^{2}$ bond presents the electronic properties. It can be seen that Figure 1 (a) is covered with a higher amount of darker particles, in comparison to Figure 1 (b). These results may suggest that using higher power in the PECVD process leads to a higher $\mathrm{sp}^{3}$ structure. Further, Figure 1 (c and d) demonstrates the top surface of the coating on the Al5052 substrate under identical deposition conditions as those for Figure 1 ( $a$ and $b$ ). It can be observed that the two images have uniform and homogenous coverages with a stripe-like structure, which is considerably different than island-shaped structure in the SS316 substrate. These images clearly suggest that the types of substrate are a predominant factor in the morphology of the DLC coating. However, the deposition conditions also play important roles. For instance, Figure 1 (a) and (c) are prepared under identical conditions using different substrates, but the morphology of the samples is completely different (island versus stripe).
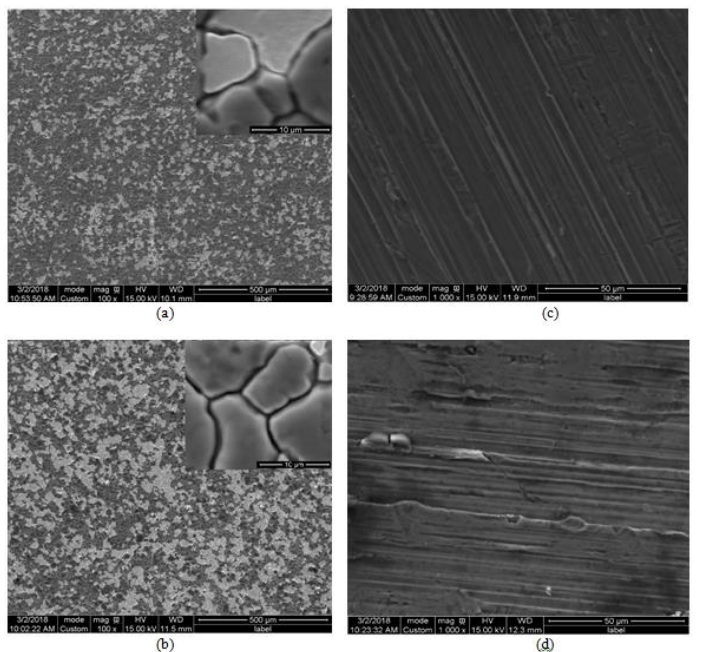

Figure 1. SEM images of coated films of DLC deposited SS316 substrates with plasma power intensity of (a) $250 \mathrm{~W}$ and (b) $1000 \mathrm{~W}$, whereas (c) and (d) for coated films of DLC deposited on A15052 substrates with plasma intensities of 250 and $1000 \mathrm{~W}$, respectively 


\section{X-ray Analysis}

Figures 1 (a) and (b) show the XPS spectra of DLC films deposited on SS316 substrates for plasma power intensities of $250 \mathrm{~W}$ and $1000 \mathrm{~W}$, respectively, with a fixed carrier gas (argon) ratio of $30 \%$. The coating films are obtained under a deposition time of $74 \mathrm{~min}$. Since the surface properties of the DLC films are strongly influenced by the ratios between the $\mathrm{sp}^{3}$ and $\mathrm{sp}^{2}$ of the carbon bonds, it can be expected that DLC with higher $\mathrm{sp}^{2}$ carbon bonds will show graphene-like properties. It can be observed from Figure 1 (a-d) that the curve peak of DLC film deposited is deconvoluted into two components, which indicate the existences of different carbon bonds including $\mathrm{sp}^{2}$ and $\mathrm{sp}^{3}$. It can be observed from Figure 1 (a) that about $81 \%$ of the DLC coated film deposited on the SS316 is $\mathrm{sp}^{2}$ carbon bonds. However, increasing the deposition power intensity to $1000 \mathrm{~W}$ lowered the amount of graphene-like bonds in the coating films by $15 \%$. Further, figure 1 (c) shows curve peaks at 284 corresponds to the $\mathrm{sp}^{2}$ binding energy on its spectrums, while the peak of DLC deposited with $1000 \mathrm{~W}$ has been shifted to the higher binding energy of $285 \mathrm{eV}$. It can be seen that the percentage of $\mathrm{sp}^{2}$ is $70.9 \%$ in the coated samples produced with $250 \mathrm{~W}$, while the DLC coatings obtained with $1000 \mathrm{~W}$ contain $58.7 \% \mathrm{sp}^{3}$ bonds. On the other hand, the second peak components occur at $286 \mathrm{eV}$, indicating the $\mathrm{C}=\mathrm{O}$ bond in the coating film due to contamination. This suggests that a higher power intensity of $1000 \mathrm{~W}$ can result in incensing of the $\mathrm{sp}^{3}$ bond in the DLC films. Further, these results may suggest that the metallic-substrate material and the depositionpower intensity can impact the deposited-film properties.

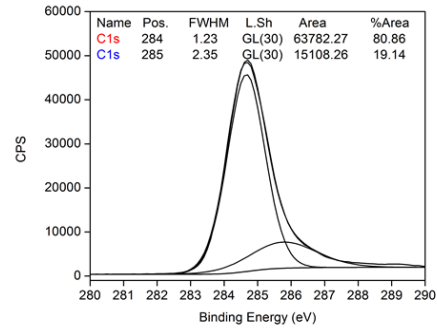

(a)

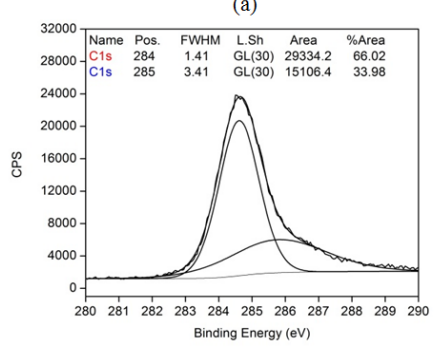

(b)

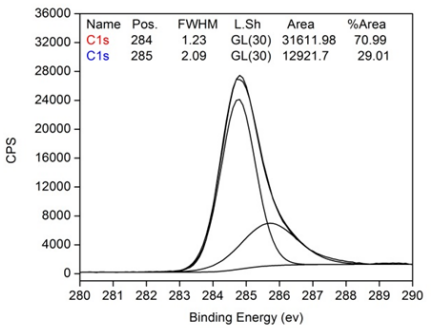

(c)

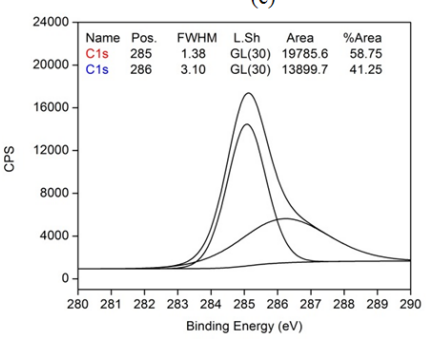

(d)
Figure 2. XPS analysis spectra of coating films of DLC with different power intensities (a) $250 \mathrm{~W}$ and (b) $1000 \mathrm{~W}$ deposited on SS316 substrates. Whereas coatings deposited on Al5052 substrates with power intensity of (c) $250 \mathrm{~W}$ and (d) $1000 \mathrm{~W}$. Deposition conditions: $\mathrm{CH}_{4}$ is a precursor gas, argon gas percentage of $30 \%$, time of $74 \mathrm{~min}$, and voltage $120 \mathrm{~V}$.

\section{Wettability}

Water management is a crucial issue inside operating PEM Fuel cells. The wettability and water repellency of the bipolar plates are important surface properties for water removal [16].
Therefore, the DLC coatings of the bipolar plate coatings surface must exhibit hydrophobicity behavior and water repellency. The surface wettabilities of the DLC coatings on different Al5052 and SS316 substrates are evaluated as in Table 2, showing the average values of the water contact angles $\left(\theta^{\circ}\right)$ for the coated surface of SS316 and A15052 substrates. The angles vary from $80^{\circ}$ to $82^{\circ}$ for the SS316 substrate, and from $76^{\circ}$ to $91^{\circ}$ for A15052 under different plasma power intensities. Table 2 may suggest that the substrate material has a strong impact on the surface wettability characteristics. It demonstrates that increasing the deposition power intensity results in lowering the contact-angle values due to the diamond-like carbon structure [17]. This observation is found to be in good agreement with the XPS analysis discussed above, which showed that a higher percentage of $\mathrm{sp}^{3}$ bonds in the coating with a higher power intensity of $1000 \mathrm{~W}$ in comparison to $250 \mathrm{~W}$. Further, it is seen that coated films deposited with a lower power intensity of $250 \mathrm{~W}$ results in a higher contact angle of $91^{\circ}$.

TABLE 2: STATIC CONTACT ANGLE $(\Theta)$ OF DLC DEPOSITED ON AL5052 AND SS316 SUBSTRATES

\begin{tabular}{|c|l|c|c|c|c|}
\hline \multicolumn{4}{|c|}{ Deposition Parameters } & $\begin{array}{c}\text { Substrate } \\
\text { Materials } \\
\text { SS316 }\end{array}$ & $\begin{array}{c}\text { Substrate } \\
\text { Materials Al5052 }\end{array}$ \\
\hline $\begin{array}{c}\text { Power } \\
(\text { W })\end{array}$ & $\begin{array}{l}\text { H/C } \\
\text { gas }\end{array}$ & $\begin{array}{c}\text { Ar } \\
(\%)\end{array}$ & $\begin{array}{l}\text { Time } \\
(\text { min })\end{array}$ & $\begin{array}{c}\text { Contact angle } \\
\left({ }^{\circ}\right.\end{array}$ & $\begin{array}{c}\text { Contact angle } \\
\left({ }^{\circ}\right)\end{array}$ \\
\hline 250 & $\mathrm{CH} 4$ & 30 & 74 & 82 & 91 \\
\hline 1000 & $\mathrm{CH} 4$ & 30 & 74 & 80 & 76 \\
\hline
\end{tabular}

\section{CONCLUSIONS}

The effect of power intensity on the carbon composite coatings deposited on aluminum (A15052) and stainless steel (SS316) substrates has been investigated. Adhesion, SEM, XPS, and wettability measurements have been conducted to understand the characteristics and the compositions of the deposited coatings. It has been observed that coatings generated from $\mathrm{CH}_{4}$ provide better adhesion than those coatings produced from $\mathrm{C}_{2} \mathrm{H}_{2}$ gas. Results suggest that the ratio between $\mathrm{sp}^{2}$ and $\mathrm{sp}^{3}$ bonds in the DLC coatings is strongly affected by the plasma power intensity. It has been found that a large percentage $\mathrm{sp}^{3}$ (diamond-like) in the coating is produced at a high power density at the cost of the $\mathrm{sp}^{2}$ bond (graphenelike). Therefore, the surface morphology and composition of the DLC coatings are strongly influenced by the deposition parameters and material of the metallic substrates. The coatings generated under power intensity of $250 \mathrm{~W}$ shows stronger adhesion with the metallic A15052 and SS316 substrates than those produced higher power of $1000 \mathrm{~W}$. Further, the DLC coatings deposited on metallic substrates demonstration hydrophobicity properties with a contact angle of between $80^{\circ}$ of $90^{\circ}$.

\section{REFERENCES}

[1] J. a. M. Spendelow, "Fuel Cell System Cost-2013", DOE Fuel and Cell Technologies Office Record, Record \# 13012.

[2] S. Chunhui, P. Mu, Y. Qin, and Y. Runzhang, "Studies on Preparation and Performance of Sodium Silicate/Graphite Conductive Composites," J. Comp. Mat., vol. 40, pp. 839-848, May 1, 2006. doi: $10.1177 / 0021998306061296$. 
[3] D. J. L. Brett and N. P. Brandon, "Review of Materials and Characterization Methods for Polymer Electrolyte Fuel Cell Flow-Field Plates," J. Fuel Cell Sci. Technol., vol. 4, pp. 29-44, Feb. 2006. doi: 10.1115/1.2393303.

[4] S. Karimi, N. Fraser, B. Roberts, and F. Foulkes, "A Review of Metallic Bipolar Plates for Proton Exchange Membrane Fuel Cells: Materials and Fabrication Methods," Adv. Mater. Sci. Eng., vol. 2012, p. 22, 2012. doi: $10.1155 / 2012 / 828070$

[5] R. L. Borup and N. E. Vanderborgh, "Design and Testing Criteria for Bipolar Plate Materials for Pem Fuel Cell Applications,” MRS Proceedings, vol. 393, p. 151, 1995. doi: 10.1557/PROC-393-151

[6] C. C. Wang, "Novel Structured Metal Bipolar Plates for Low Cost Manufacturing," Project ID\# : FC105 2014.

[7] R. Paul, S. Hussain, S Majumder, S Varma, and A. K. Pal, "Surface plasmon characteristics of nanocrystalline gold/DLC composite films prepared by plasma CVD technique," Mater. Sci. Eng. B: Solid, vol. 164, pp. 156-164, 2009. doi: 10.1016/j.mseb.2009.09.009.

[8] G. A. Viana, et al., "Diamond-like carbon deposited by plasma technique as a function of methane flow rate," Diamond Relat. Mater., vol. 19, nos. 7-9, pp. 756-759, Jul. - Sept. 2010. doi: 10.1016/j.diamond.2010.01.043.

[9] D. Caschera, F Federici, S Kaciulis, L Pandolfi, A Cusmà, and G. Padeletti, "Deposition of Ti-containing diamond-like carbon (DLC) films by PECVD technique," Mater. Sci. Eng. C, vol. 27, nos. 5-8. pp. 1328-1330, Sept. 2007. doi: 10.1016/j.msec.2006.06.027.

[10] T. Fukutsuka, T. Yamaguchi, S.-I. Miyano, Y. Matsuo, Y. Sugie, and Z. Ogumi, "Carbon-coated stainless steel as PEFC bipolar plate material," J. Power Sources, vol. 174, no. 1, pp. 199-205, Nov. 2007. doi: 10.1016/j.jpowsour.2007.08.096.

[11] C.-Y. Chung, S.-K. Chen, P.J. Chiu, M.-H. Chang, T.-T. Hung, and T.-H. Ko, "Carbon film-coated 304 stainless steel as PEMFC bipolar plate," J. Power Sources, vol. 176, no. 1, pp. 276-281, Jan. 2008.

doi: 10.1016/j.jpowsour.2007.10.022.

[12] Md. K. Hassan, B. K. Pramanik and A., "Electrical Resistivities of the DiamondLike Carbon Films Fabrciated from Methane and Acetylene Using RF Plasma," New Diamond Front. Carbon Technol., vol. 16, no. 4, pp. 211-219, Jan. 2006.

[13] J. R. Mawdsley, J. D. Carter, X. Wang, S Hiyogi, C. Q. Fan, R. Koc, and G. Osterhout, "Composite-coated aluminum bipolar plates for PEM fuel cells," J. Power Sources, vol. 231, no. 1,pp. 106-112, Jun. 2013. doi: 10.1016/j.jpowsour.2012.12.074.

[14] S.-J. Lee, C.H. Huang and Y.P. Chen., "Investigation of PVD coating on corrosion resistance of metallic bipolar plates in PEM fuel cell," J. Mater. Process. Technol., vol. 140, nos. 1-3, pp. 688-693, Sept. 2003.

doi: 10.1016/S0924-0136(03)00743-X.

[15] M. Aksak S. Kir and Y. Selamet, "Effect of the growth temperature on carbon nanotubes grown by thermal chemical vapor deposition method." J. Optoelectron. Adv. Mater. Symp., vol. 1 no. 3, pp. 281-284, 2009.

[16] S. A. Shakhshira, Y. Wang, I. E. Alaefour, and X. Li, "The Influence of Channel Wettability on Two-Phase Flow and Polymer Electrolyte Membrane Fuel Cell Performance," ECS Transactions, vol. 42, pp. 109-115, 2012.

doi: 10.1149/1.4705486.

[17] J. Martí-González and E. Bertran, "Mechanical and Surface Characterization of Diamond-Like Carbon Coatings onto Polymeric Substrate," arXiv preprint arXiv:1509.08512, 2015. 